the University of Brno, already well known on the Continent for his contributions to the modern philosophical approach to social problems. Perhaps better known in Britain is the dean, Dr. V. Lesný, previously professor of Oriental studies at Prague, who has travelled much in India and written several works on Indian culture, some of which have appeared in English. The best known of these, is his study of Rabindranath Tagore. Olomouc is not a new centre of culture. It was the seat of an ancient Czechoslovak school in the sixteenth century. In the seventeenth century this became a catholic seminary, and its presses produced some early Slavonic books. The eighteenth century scientific journal, Monatliche Auszüge, edited by Joseph Petrasche, was published at Olomouc, then better known by its German name Olmütz.

\section{Geology at University College, Swansea}

IT is announced that Dr. Duncan Leitch, at present lecturer in geology in the University of Glasgow, has been appointed to succeed Prof. T. Neville George as professor of geology at Swansea. Dr. Leitch was trained under the late Prof. J. W. Gregory, with whom he carried out researches on the metallic minerals of Kirkcudbrightshire and on some caves of Galloway. Most of his subsequent work has related to the palæontology and stratigraphy of the Carboniferous rocks, especially of Scotland, where in collaboration with Dr. John Weir he carried out an exhaustive study of the non-marine lamellibranchs of the Coal Measures and provided a sound basis for the correlation of the seams. In an important series of papers he has developed statistical methods, which are proving of wide application, for the study of fossils. There is great scope for statistical research in palæontology and in other branches of geology; and at Swansea, in close access to the areas where the standard sequence of Coal Measures zones was established, he will find good opportunities to extend these investigations.

\section{Colonial University Grants Advisory Committee}

THE Secretary of State for the Colonies has, in accordance with a recommendation of the Commission on Higher Education in the Colonies, appointed a Colonial University Grants Advisory Committee to advise him on the expenditure of United Kingdom funds for the development of higher education in the Colonies. On the academic aspects the Committee will be guided by the opinion of the Inter-University Council for Higher Education in the Colonies. The secretary of the Inter-University Council, Mr. Walter Adams, has been appointed secretary of the new Committee also, and the following have been appointed members: Sir Hector Hetherington, vice-chancellor of the University of Glasgow (chairman); Miss Myra Curtis, principal of Newnham College, Cambridge; Lord Hailey; Sir James Irvine, vice-chancellor of the University of St. Andrews; Sir Walter Moberly, chairman of the University Grants Committee; Dr. Keith Murray, rector of Lincoln College, Oxford; Prof. D. Hughes Parry, vice-chancellor of the University of London; Dr. R. E. Priestly, vice-chancellor of the University of Birmingham ; Mr.D.J. Sloss, vice-chancellor of the University of Hongkong; Mr. C. W. M. Cox, educational adviser to the Secretary of State for the Colonies; Mr. J. B. Williams, Finance Department, Colonial Office.

\section{Experiments on Cosmic Rays in High-Flying Air- craft}

A BRIEF announcement has been issued by Dr. Gilbert Grosvenor and Dr. W. F. G. Swann in a News Bulletin of the National Geographic Society of Washington of some experiments on the origin of the meson component of the cosmic rays. The National Geographic Society, the Bartol Foundation and the U.S. Army co-operated in the experiments, which were made in a series of flights in a $B 29$ aircraft at places, ranging from Northern Chile to Southern Canada, from the magnetic equator up to mag. lat. $48^{\circ} \mathrm{N}$. and at altitudes up to $33,000 \mathrm{ft}$. The apparatus consisted of a number of coincidence counters arranged to record penetrating particles of which the direction of motion was in or near the vertical. The soft component (electrons and photons) was previented from reaching the counters by a sufficient thickness of lead shielding. At 33,000 ft. the observed intensity of the mesons, using this particular experimental arrangement, was observed to increase by 33 per cent in going from mag. lat. $0^{\circ}$ to mag. lat. $48^{\circ}$, and 50 per cent at $25,000 \mathrm{ft}$. The absolute change in intensity with latitude, in contrast with the above values of the relative changes, was greater at the higher altitude than at the lower.

The results show, in accordance with previous views, that a considerable fraction of the meson component is produced by primary charged particles, presumably protons, of such an energy that some of them are appreciably deflected by the magnetic field in approaching the earth. The decrease in the percentage variation of the intensity with latitude at increasing altitudes is attributed to the presence of a primary component which produces mesons in lead but is not sensitive to the magnetic field of the earth and is rapidly absorbed between 33,000 and $25,000 \mathrm{ft}$. This radiation could be made up of photons. The authors prefer, however, to attribute it to protons of great energy. In this case the observations suggest that the cross-section for the production of mesons by fast protons increases rapidly with increasing energy. In support of this view it is found that there is no increase in the meson intensity at $33,000 \mathrm{ft}$. at latitudes higher than $48^{\circ} \mathrm{mag}$. N. A proton of such an energy that it could enter the earth's atmosphere at this latitude would not be stopped by the matter composing the atmosphere down to $33,000 \mathrm{ft}$. plus the lead of the apparatus if it loses energy only by the normal processes of ionization. The observed absorption must therefore be attributed to other processes which, the authors suggest, are connected with meson production.

\section{Behaviour : An International Journal of Comparative Ethology}

INTEREST in the study of animal behaviour (ethology) is growing rapidly. The results of comparative behaviour studies have in the past been scattered throughout a number of periodicals and other publications. The German Zeitschrift für Tierpsy. chologie was hitherto the only European journal devoted exclusively to the publication of modern behaviour studies; and during its short existence, it demonstrated clearly that a special journal of this kind fulfils a most important function in stimulating and promoting the study of the subject with which it deals ; but its future is now in doubt. It has accordingly been decided to found a new international journal of comparative ethology to be called Behaviour. 